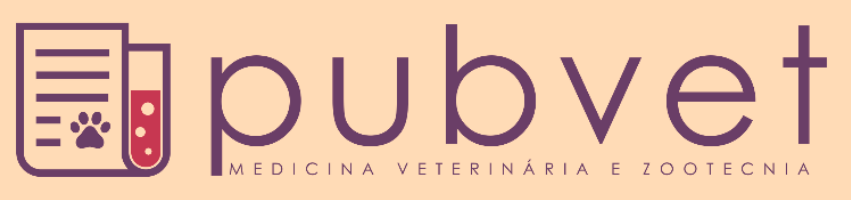

https://doi.org/10.31533/pubvet.v13n9a417.1-6

\title{
Avaliação dos parâmetros produtivos de garrotes mestiços em confinamento, alimentados com diferentes dietas a base de milho em grãos
}

\author{
Acácia de Oliveira Machado ${ }^{1} \bullet$, Mateus Pimentel de Andrade ${ }^{\bullet}$, Leonardo da Rocha \\ $\operatorname{Gripa}^{2}{ }^{\circ}, \operatorname{Ramon}_{\text {de Sousa }} \operatorname{Rego}^{3 \odot}$, Fernanda Giácomo Ragazzi $^{3 *} \bullet$ \\ ${ }^{I}$ Discente do curso de Medicina Veterinária, Universidade Iguaçu - Campus V. Itaperuna/RJ. Brasil. \\ ${ }^{2}$ Médico Veterinário do curso de Medicina Veterinária, Universidade Iguaçu-Campus V. Itaperuna/RJ. Brasil. \\ ${ }^{3}$ Docente do curso de Medicina Veterinária, Universidade Iguaçu-Campus V. Itaperuna/RJ. Brasil. \\ *Autor para correspondência, E-mail:ragazzi.fernanda@gmail.com
}

\begin{abstract}
Resumo. O objetivo do presente experimento foi avaliar a influência do fornecimento do milho em grão sobre o desempenho produtivo de bovinos de corte em sistema de confinamento para avaliar os parâmetros zootécnicos de ganho de peso médio (GMD $\mathrm{kg} / \mathrm{dia}$ ), peso de carcaça (PC) e rendimento de carcaça quente (RCQ - \%). Utilizaram-se 24 bovinos mestiços confinados durante 65 dias, separados, de acordo com a alimentação, sexo, castrado ou não castrado, compondo quatro tratamentos distintos: T1: 10 garrotes machos não castrados alimentados com dieta restritiva de milho em grãos; T2: 4 garrotes machos não castrados alimentados com milho em grãos, forragem e CT600, T3: 5 garrotes machos castrados alimentados com milho em grãos, forragem e proteinado e T4: 5 fêmeas alimentadas com milho em grãos, forragem e proteinado. O grupo T1 apresentou valores superiores de GMD (1,32 kg/dia), PCQ (113,13 kg) e RCQ (50,42\%). O uso da alimentação com milho em grãos é eficiente para bovinos machos não castrados mesmo em raças SRD em confinamento, apresentando resultados satisfatórios em rendimentos produtivos.
\end{abstract}

Palavras chave: bovinos mestiços, confinamento, grão inteiro

\section{Evaluation of productive parameters of crossbred cattle finished in feedlot fed different diets with grain corn}

\begin{abstract}
The objective of the present experiment was to evaluate the influence of maize grain supply on animal performance of beef cattle in feedlot system to evaluate the average weight gain (ADG - kg/day, hot carcass weight (HCW) and hot carcass dressing (HCD, $\%)$. Twenty-five crossbred cattle in finished for 65 days, separated according to feeding, sex, castrated or bulls, comprising four different treatments: T1: 10 bulls fed a restrictive grain corn diet; T2: 4 bulls, fed on corn, forage and CT600, T3: 5 steers fed grain corn, forage and protein, and T4 5 cows fed corn, forage and protein. The T1 group presented higher values of ADG (1.32 kg/day), HCW (113.13 kg) and HCD (50.42\%). The use of maize grain feed is efficient for bulls even in SRD breeds in feedlot, presenting satisfactory results in productive income.
\end{abstract}

Key words: crossbred cattle, feedlot, whole grain 


\title{
Evaluación de parámetros productivos de terneros mestizos en sistema de cebadero y alimentados con dietas a base de granos de maíz
}

\begin{abstract}
Resumen. El objetivo del presente experimento fue evaluar la influencia del suministro de granos de maíz en cuanto al desempeño productivo de bovinos de corte en sistema de cebadero para evaluar los parámetros zootécnicos de ganancia de peso medio (GMD $\mathrm{kg} / \mathrm{d}$ ía), peso de la canal (PC) y rendimiento de canal caliente (RC, \%). Se utilizó 24 bovinos mestizos confinados durante 65 días, separados, de acuerdo con la alimentación, sexo, castrado o entero, componiendo cuatro tratamientos distintos: T1: 10 terneros machos enteros alimentados con dieta restrictiva de maíz en granos; T2: 4 terneros machos enteros alimentados con maíz en granos, forraje y CT600, T3: 5 terneros machos castrados alimentados con maíz en granos, forraje y proteínado y T4 5 hembras alimentadas con maíz en granos, forraje y proteinado. El grupo T1 presentó valores superiores de GMD (1,319 $\mathrm{kg} / \mathrm{d}$ ía), PC (113,13 kg) y RC (50,42\%). El uso de la alimentación con maíz en granos es eficiente para bovinos machos enteros incluso siendo mestizos en sistema de cebadero, presentando resultados satisfactorios en rendimientos productivos.
\end{abstract}

Palabras clave: bovinos mestizos, cebadero, grano entero

\section{Introdução}

No Brasil o sistema de confinamento de bovinos para corte é uma das práticas utilizadas dentro da cadeia de produção da carne bovina, por momento da sazonalidade das pastagens, desenvolvendo um papel relevante nos processos socioeconômico (Prado, 2010). Entretanto, o desenvolvimento dessa prática ainda requer a obtenção de melhores índices zootécnicos, principalmente frente à falta de uma política agropecuária adequada aos produtores e ao incipiente conhecimento científico quanto a eficiência no manejo nutricional, sanitário e produtivo deste sistema. O sistema de confinamento visa reduzir o tempo necessário para abate do animal e assim reduzir o ciclo produtivo, o que resultaria numa maior velocidade de entrada e saída dos animais e um maior ganho de capital (Prado \& Moreira, 2002; Silva et al., 2010).

Segundo ANUALPEC (2019), houve aumento da ordem de $170 \%$ no número de bovinos confinados no Brasil, entre 1988 e 2018. A habilidade de ganho de peso de bovinos em confinamento foi influenciada pelo nível nutricional a que foram submetidos (Rotta et al., 2009), evidenciando a busca pela melhoria da eficiência na produção de carne como novo padrão para a fase final da pecuária de corte.

A bovinocultura de corte possui duas fases iniciais até chegar à fase da terminação ou engorda. A fase de cria compreende a reprodução, nascimento dos bezerros e a fase de desmame, quando então o bezerro atinge aproximadamente 25 a $35 \%$ do peso de abate, e a fase de recria que objetiva completar o desenvolvimento ósseo do animal e também de grande parte de sua musculatura, tratando-se, em termos de planejamento da idade após o desmame e de 1 a 2 anos (Brito et al., 2002; Butterfield, 1966; Lira et al., 2013). E por último a fase propriamente dita de terminação ou de engorda que visa preparar o animal para o abate ou a venda que pode ser realizada a pasto, geralmente no período chuvoso e base do sistema de confinamento no período seco do ano.

O manejo estratégico em sistemas de confinamento deve ser realizado preferencialmente por um período curto, compreendendo de 90 a 120 dias, de forma que o animal ganhe aproximadamente $1 \mathrm{~kg}$ no peso corporal por dia, até a data planejada para a venda ou o abate, quando estão com 400 a $500 \mathrm{~kg}$ de peso vivo. Devido à grande exigência do mercado interno e externo quanto à demanda na produção de bovinos de corte os sistemas de confinamento têm aumentado. Contudo, devido aos custos com a estrutura, esta prática, constituiu-se de uma atividade limitada a poucas regiões do Brasil (Prado, 2010).

Em sistemas de confinamentos existe uma diversidade de dietas realizadas visando maior ganho de peso por menor tempo do animal confinado. Nos últimos anos dietas ricas em concentrados com pouca quantidade de volumoso vêm se tornando mais frequente (Monteschio et al., 2017; Ornaghi et al., 2017; Rivaroli et al., 2017). Isto pode se explicar por que um dos problemas no confinamento é a produção de alimento volumoso, pois demandam mão-de-obra, dificuldades no armazenamento, desperdícios 
consideráveis devido à fermentação do capim e elevados custo de produção no processo final (Valente, 1991). Devido a isto, novos recursos para diminuir essas dificuldades financeiras e estruturais vêm despertando interesse dos criadores de gado de corte, de pesquisadores e empresários do ramo, dentre essas práticas, destaca-se o fornecimento de dietas a base de grãos de milho com elevados níveis de concentrado (Fugita et al., 2018; Monteschio et al., 2017; Ornaghi et al., 2017; Rivaroli et al., 2017).

As recomendações nutricionais desta dieta a base de milho em grãos, procuraram promover melhorias quanto a eficiência fermentativa em nível de ambiente ruminal, contudo, deve-se avaliar condições de produção destes grãos nas diferentes regiões brasileiras de modo a ser uma prática economicamente viável. Por isso, é importante conhecer o sistema que demonstra melhor resposta à predição, em função das exigências e produções esperadas nos diversos sistemas de produção nacional (Brito et al., 2002; Rotta et al., 2009). Dietas com elevado nível de concentrado vem apresentando inúmeros benefícios já que permitem um melhor rendimento de carcaça, composição física, acabamento, conformação e melhor rendimento de cortes comerciais (Barcellos et al., 2019; Eiras et al., 2017; Fugita et al., 2018; Monteschio et al., 2017; Monteschio et al., 2019; Souza et al., 2018). Segundo Missio et al. (2010) e Missio et al. (2015), altos níveis de concentrado na dieta diminuem a maturidade fisiológica e aumentam a participação de cortes nobres na carcaça, diminuindo a textura e melhorando o aspecto visual de carne de bovinos não castrados.

O uso da dieta a base de milho inteiro vem sendo uma técnica que além de melhorar o desempenho produtivo, também facilita o processo de confinamento, onde há a redução de gastos em função da menor demanda de mão de obra, aquisição e manutenção de maquinário e da oportunidade de regiões que não tem volumoso de realizar as práticas de confinamento (Abrahão et al., 2005; Moletta et al., 2014; Pinto et al., 2011). Geralmente, os produtores optam por utilizar concentrados como farelo de soja, fubá de milho e sal mineral na época da seca, por ser esse período, crítico para alimentação exclusiva com forragem, contudo, os custos com essa alimentação, acabam por desestimular muitos produtores a confinar animais e com isso, acabam tendo como consequência perdas econômicas devido à produção de animais magros, velhos e sem qualidade na carcaça.

O objetivo do presente experimento foi avaliar a influência do fornecimento do milho em grão quanto ao desempenho produtivo de bovinos de corte em sistema de confinamento, separados em quatro grupos compostos por bovinos mestiços (SRD), para avaliação dos parâmetros zootécnicos de ganho de peso médio, peso de carcaça e rendimento de carcaça.

\section{Material e métodos}

O experimento foi conduzido na Fazenda Cachoeira Bonito no município de Miracema, RJ, no período de agosto a outubro de 2018, após ser submetido e aprovado pela CEUA. Utilizou-se 24 bovinos mestiços (sem raça definida) confinados durante 65 dias, sendo 15 dias de adaptação (Tabela 1) e 50 dias de confinamento, separados em quatro áreas de tamanhos conhecidos, de acordo com a alimentação, sexo, castrado ou inteiro, compondo quatro tratamentos: T1: 10 garrotes machos inteiros alimentados com dieta restritiva de milho em grãos; T2: 4 garrotes machos inteiros alimentados com milho em grãos, forragem e CT600 (concentrado energético-proteico da empresa Nutrimais para bovinos de corte em confinamento); T3: 5 garrotes machos castrados alimentados com milho em grãos, forragem e proteinado e T4 5 fêmeas alimentadas com milho em grãos, forragem e proteinado.

Tabela 1. Fase de adaptação dos bovinos

\begin{tabular}{lcccc}
\hline Alimentos & $1^{\circ}$ Semana & $2^{\circ}$ Semana & $3^{\circ}$ Semana & Início do experimento \\
\hline Concentrado $^{1}$ & $1,5 \%$ peso vivo & $2 \%$ peso vivo & $2,5 \%$ de peso vivo & até $8 \mathrm{~kg} /$ dia $/$ animal \\
Volumoso $^{2}$ & $20 \mathrm{~kg} /$ animal & $12 \mathrm{~kg} / \mathrm{animal}$ & $6 \mathrm{~kg} / \mathrm{animal}$ & até $6 \%$ do peso vivo \\
Sal proteínado $^{3}$ & $100 \mathrm{~g} /$ animal & $100 \mathrm{~g} / \mathrm{animal}$ & $100 \mathrm{~g} \mathrm{sal} / \mathrm{animal}$ & $100 \mathrm{~g} /$ animal \\
\hline
\end{tabular}

${ }^{1}$ concentrado: mistura composta por $85 \%$ de milho em grãos e $15 \%$ de ração grão inteiro Nutrimais. ${ }^{2}$ volumoso:mistura composta por cana-de-açúcar e capim elefante cv. Napier. ${ }^{3}$ sal proteinado fos 170 da Nutrimais.

O período de adaptação foi importante para que os animais passassem por uma dieta de transição visando adequar à condição corporal e redução dos efeitos de ganho compensatório. Principalmente para o grupo T1 composto por uma dieta restritiva em grãos, que ao final do período de adaptação foi retirado 
o volumoso, a adaptação auxiliou na redução de distúrbios metabólicos, mas vale ressaltar que mesmo com essa adaptação, 3 bovinos apresentaram quadro de acidose, sendo tratados e recuperados imediatamente após a visualização do quadro. Além da adaptação com a dieta apropriada a cada tratamento experimental, foi realizado vermifugação e vacinação do gado com o seguinte protocolo sanitário: ricobendazole, doramectina e botulismo, recomendado e acompanhado pelo médico veterinário da propriedade.

Foi avaliado o ganho de peso médio diário (GMD - kg/dia), peso de carcaça quente (PC - kg) e rendimento de carcaça quente (RCQ - \%). Para avaliação do GMD foi realizado duas pesagens, a inicial e a final, realizadas com os animais em jejum de água e comida num período de 18 horas para melhor resultado dos valores obtidos por animal e por dias de confinamento. Para o peso de carcaça, os animais após o período experimental foram abatidos e pós as práticas frigoríficas, pesados. Com o peso da carcaça dos bovinos, obteve-se o rendimento de carcaça quente.

Para apresentação dos resultados, optou-se pela estatística descritiva com média, variância e desvio padrão, com apresentação em tabelas para melhor visualização dos dados obtidos.

\section{Resultados e discussão}

Com relação ao GMD, houve variação quando a este índice nos diferentes grupos avaliados (Tabela 2).

Tabela 2. Peso vivo inicial, peso vivo final e ganho de peso médio diário dos quatro grupos de bovinos avaliados

\begin{tabular}{lcccc}
\hline Parâmetros avaliados & T1 & T2 & T3 & T4 \\
\hline Peso vivo inicial, $\mathrm{kg}$ & 180 & 150 & 150 & 135 \\
Peso vivo final, $\mathrm{kg}$ & 226,15 & 226,31 & 197,96 & 190,05 \\
Ganho de peso médio diário - Kg/dia & 1,32 & 1,03 & 1,07 & 0,92 \\
\hline
\end{tabular}

Pode-se observar que o grupo T1 composto por machos inteiros alimentados com dieta restritiva de milho em grãos apresentou resultado superior aos demais grupos, seguido do grupo T2 composto por machos inteiros alimentados com milho em grãos, forragem e CT600, seguido do grupo T3 (machos castrados) alimentado com milho em grãos, forragem e proteinado e pelo grupo T4 fêmeas alimentadas com milho em grãos, forragem e proteinado.

Nota-se que o grupo composto por fêmeas, apresentou menor GMD, esse resultado em comparação com os machos, era esperado em função da deposição de carne e produção hormonal. Contudo, o GMD entre os grupos de macho inteiros, foi diferente do que esperado com este trabalho. Sendo maior GMD no grupo de machos inteiros com forragem e CT600 em comparação ao grupo apenas de alimentação com milho em grãos.

Esses grupos de animais tiveram diferentes ganhos de peso que numa breve comparação com outros artigos, demonstraram ser importantes para maiores pesquisas e está dentro dos padrões de variação nutricional desde uma alimentação a base de forragem até uma alimentação a base de concentrado.

Por exemplo, os grupos de bovinos neste trabalho apresentaram valores superiores aos encontrados por Moreira et al. (2015), com valores médios de 0,64 kg/dia de GMD em bovinos em manejo alimentar de pastejo de Panicum maximum cv. Mombaça terminados os 30 dias de adaptação os animais recebendo $6 \mathrm{~kg}$ de ração (constituída de: $73 \%$ de milho, $20 \%$ de soja, $7 \%$ de núcleo mineral). Essa variação no ganho de peso médio diário pode ser explicada devido ao manejo alimentar distinto dos referentes grupos, mas mostrando a potencialidade da alimentação com milho em grãos em detrimento de forragem e ração apenas. Outro comparativo realizado, foi com o experimento de Silva et al. (2012) em que os autores verificaram o GMD de 1,07 kg/dia, sendo o manejo alimentar presente a base de silagem de capim Mombaça, grão de milho triturado, farelo de soja, farelo do mesocarpo do Babaçu, mostrando resultados inferiores ao encontrado neste trabalho.

Tabela 3. Peso de carcaça e rendimento de carcaça quente dos grupos de bovinos avaliados

\begin{tabular}{lcccc}
\hline Parâmetros avaliados & T1 & T2 & T3 & T4 \\
\hline Peso de carcaça - Kg & 113,13 & 114,11 & 101,65 & 88,27 \\
Rendimento de carcaça quente - \% & 50,42 & 50,04 & 44,92 & 46,45 \\
\hline
\end{tabular}


Pode-se observar que seguindo a mesma ordem da tabela anterior, o grupo T1 apresentou maior rendimento de carcaça com 50,42\% e o grupo T2 com 50,04\%, mostrando superioridade em temos de machos inteiros com alimentação de milho em grãos. O grupo T4 apresentou menor rendimento de carcaça, com apenas $46,45 \%$, ressaltando que este grupo foi composto por fêmeas e era esperado menor rendimento de carcaça. Ao comparar macho inteiro e macho castrado, pode-se observar que os machos inteiros apresentaram maior rendimento de carcaça.

\section{Conclusão}

Conclui-se com este trabalho que o uso da alimentação com milho em grãos é eficiente para bovinos machos inteiros em confinamento quando ao rendimento de carcaça e ganho de peso. Contudo, para fêmeas, os resultados não foram satisfatórios, devendo-se planejar os grupos de bovinos, visando maiores ganhos produtivos e econômicos.

\section{Referências bibliográficas}

Abrahão, J. J. S., Prado, I. N., Perotto, D. \& Moletta, J. L. (2005). Características de carcaças e da carne de tourinhos submetidos a dietas com diferentes níveis de substituição do milho por resíduo úmido da extração da fécula de mandioca. Revista Brasileira de Zootecnia, 34(5):1640-1650.

ANUALPEC. (2019). Anuário da Pecuária Brasileira (20th ed. Vol. 1). São Paulo, São Paulo, Brasil: Instituto FNP.

Barcellos, V. C., Mottin, C., Prado, R. M., Schenkel, T., Viana, C. M. S., Vital, A. C. P. \& Prado, I. N. (2019). How the perception of quality for beef evaluated by the buyer at the time of purchase: Study in three Brazilian cities of different sizes - Curitiba, Campo Mourão and Palotina. Acta Scientiarum Animal.Sciences, 41(e46533):1-11.

Brito, R. M., Sampaio, A. A. M., Cruz, G. M., Alencar, M. M., Barbosa, P. F. \& Barbosa, R. T. (2002). Comparação de sistemas de avaliação de dietas para bovinos no modelo de produção intensiva de carne. II-Creep feeding. Revista Brasileira de Zootecnia, 31:1002-1010.

Butterfield, R. M. (1966). Relative growth in beef cattle. Australian Veterinary Journal, 42(3):87-90.

Eiras, C. E., Mottin, C., Passetti, R. A. C., Torrecilhas, J. A., Souza, K. A., Guerrero, A. \& Prado, I. N. (2017). How does the dietary cottonseed hull affect the animal performance of young bulls finished in a high-concentrate system? Animal Production Science, 57:1719-1724.

Fugita, C. A., Prado, R. M., Valero, M. V., Bonafé, E. G., Carvalho, C. B., Guerrero, A. \& Prado, I. N. (2018). Effect of the inclusion of natural additives on animal performance and meat quality of crossbred bulls (Angus vs. Nellore) finished in feedlot. Animal Production Science, 58(11):20762083.

Prado, I.N. \& Moreira, F. B. (2002). Suplementação de bovinos no pasto e alimentos usados ma bovionocultura (Vol. 1). Maringá, Paraná, Brasil: Eduem.

Lira, T. S., Pereira, L. S., Lopes, F. B., Ferreira, J. L., Lôbo, R. B. \& Santos, G. C. J. (2013). Tendências genéticas para características de crescimento em rebanhos Nelore criados na região do trópico úmido do Brasil. Revista Ciência Animal Brasileira, 14(1):23-31.

Missio, R. L., Brondani, I. L., Filho, D. C. A., Restle, J., Arboitte, M. Z. \& Segabinazzi, L. R. (2010). Características da carcaça e da carne de tourinhos terminados em confinamento, recebendo diferentes níveis de concentrado na dieta. Revista Brasileira de Zootecnia, 39(7):1610-1617.

Missio, R. L., Restle, J., Moletta, J. L., Kuss, F., Neiva, J. N. M., Elejalde, D. A. G. \& Miotto, F. R. C. (2015). Slaughter weights on animal performance, carcass commercial cuts and meat characteristics of cull cows. Semina: Ciências Agrárias, 36(6):3827-3842.

Moletta, J. L., Torrecilhas, J. A., Ornaghi, M. G., Passeti, R. A. C., Eiras, C. E. \& Prado, I. N. (2014). Feedlot performance of bulls and steers fed on three levels of concentrate in the diets. Acta Scientiarum Animal.Sciences, 36(3):323-328.

Monteschio, J. O., Souza, K. A., Vital, A. C. P., Guerrero, A., Valero, M. V., Kempinski, E. M. B. C. \& Prado, I. N. (2017). Clove and rosemary essential oils and encapsuled active principles (eugenol, thymol and vanillin blend) on meat quality of feedlot-finished heifers. Meat Science, 130:50-57. 
Monteschio, J. O., Vargas-Junior, F. M., Almeida, F. L. A., Pinto, L., Kaneko, I. N., Almeida, A. A. \& Prado, I. N. (2019). The effect of encapsulated active principles (eugenol, thymol and vanillin) and clove and rosemary essential oils on the structure, collagen content, chemical composition and fatty acid profile of Nellore heifers muscle. Meat Science, 155:27-35.

Moreira, P. S. A., Lourenço, F. J., Lima, C. C., Faria, F. F., El Farra, A. \& Romero, N. B. (2015). Desempenho produtivo e características de carcaça de bovinos Nelore submetidos a diferentes métodos de castração. Revista Brasileira de Ciências Agrárias, 10(4):570-575.

Ornaghi, M. G., Passetti, R. A. C., Torrecilhas, J. A., Mottin, C., Vital, A. C. P., Gurerrero, A. \& Prado, I. N. (2017). Essential oils in the diet of young bulls: Effect on animal performance, digestibility, temperament, feeding behaviour and carcass characteristics. Animal Feed Science and Technology, 234:274-283.

Pinto, A. P., Prado, I. N., Moletta, J. L., Zawadski, F., Fugita, C. A. \& Oliveira, M. G. (2011). Desempenho animal e características de carcaça de bovinos inteiros de diferentes grupos genéticos terminados em confinamento. Magistra, 23(3):92-100.

Prado, I. N. (2010). Produção de bovinos de corte e qualidade da carne (Vol. 1). Maringá, Paraná, Brasil: Eduem.

Rivaroli, D. C., Ornaghi, M. G., Mottin, C., Prado, R. M., Ramos, T. R., Guerrero, A. \& Prado, I. N. (2017). Essential oils in the diet of crossbred ( $1 / 2$ Angus vs. $1 / 2$ Nellore) bulls finished in feedlot on animal performance, feed efficiency and carcass characteristics. Journal of Agricultural Science, 9(10):205-212.

Rotta, P. P., Prado, R. M., Prado, I. N., Valero, M. V., Visentainer, J. V. \& Silva, R. R. (2009). The effects of genetic groups, nutrition, finishing systems and gender of Brazilian cattle on carcass characteristics and beef composition and appearance: a review. Asian-Australasian Journal of Animal Sciences, 22(12):1718-1734.

Silva, N. R., Ferreira, A. C. H., Faturi, C., Silva, G. F., Missio, R. L., Neiva, J. N. M. \& Alexandrino, E. (2012). Desempenho em confinamento de bovinos de corte, castrados ou não, alimentados com teores crescentes de farelo do mesocarpo de babaçu. Ciência Rural, 42(10):1882-1887.

Silva, R. R., Prado, I. N., Carvalho, G. G. P., Silva, F. F., Almeida, V. V. S., Santana Júnior, H. A. \& Abreu Filho, G. (2010). Níveis de suplementação na terminação de novilhos Nelore em pastagens: aspectos econômicos. Revista Brasileira de Zootecnia, 39(9):2091-2097.

Souza, K. A., Cooke, R. E., Aschubach, K. M., A.P., B., Schumher, T. F., Prado, I. N. \& Bohnert, D. W. (2018). Performance, health and physiological responses of newly-weaned feedlot cattle supplemented with feed-grade antibiotics or altrnative feed ingredients. Animal, 12(12):2521-2528.

Valente, J. O. (1991). Milho para silagem: tecnologia, sistema e custo de produção. EMBRAPA, 1485.

Recebido: 21 de junho de 2019.

Aprovado: 18 de julho, 2019.

Publicado: 29 de outubro, 2019.

Licenciamento: Este artigo é publicado na modalidade Acesso Aberto sob a licença Creative Commons Atribuição 4.0 (CC-BY 4.0), a qual permite uso irrestrito, distribuição, reprodução em qualquer meio, desde que o autor e a fonte sejam devidamente creditados. 